\title{
Factors influencing the retention of registered nurses in the Gauteng Province of South Africa
}

\author{
Authors: \\ Kgaogelo E. Mokoka ${ }^{1}$ \\ Valerie J. Ehlers ${ }^{1}$ \\ Martha J. Oosthuizen ${ }^{1}$ \\ Affiliations: \\ ${ }^{1}$ Department of Health \\ Studies, University of South \\ Africa, South Africa \\ Correspondence to: \\ Valerie Ehlers \\ Email: \\ ehlervj@unisa.ac.za \\ Postal address: \\ PO Box 65075, Pretoria 0165, \\ South Africa. \\ Dates: \\ Received: 12 July 2011 \\ Accepted: 04 Nov. 2011 \\ Published: 14 Dec. 2011 \\ How to cite this article: \\ Ehlers, V.J. \& Oosthuizen, \\ M.J., 2011, 'Factors \\ influencing the retention of \\ registered nurses in the \\ Gauteng Province of South \\ Africa', Curationis 34(1), Art. \\ 16,9 pages. http://dx.doi. \\ org/10.4102/curationis. \\ v34i1.16
}

C 2011. The Authors. Licensee: AOSIS OpenJournals. This work is licensed under the Creative Commons Attribution License.
Background: South Africa is a source country for many destination countries that recruit registered nurses who emigrate for personal and/or professional reasons. A large number of South African nurses belong to the baby boomer generation (born between 1943 and 1964) who will retire within the foreseeable future. Statistics from the South African Nursing Council show a decline of $42.0 \%$ in the number of nurses who completed their training in South Africa from 1996 to 2005. These aspects combine to predict a potential dire shortage of nurses in South Africa within the foreseeable future.

Objectives: Retention of registered nurses should be the focus of health-care planners to avoid crises in South Africa's health-care services. This study attempted to identify factors that would influence registered nurses' decisions to stay with their current employers in the Gauteng Province of South Africa.

Methods: An exploratory descriptive quantitative design was adopted and questionnaires were sent to a sample of nurses, registered with the South African Nursing Council (SANC), with addresses in the Gauteng Province. A total of 108 nurses completed and returned questionnaires, of whom $77(73.1 \%)$ had considered leaving their current employers.

Results: The most important factors that would influence more than $90.0 \%$ of these nurses' decisions to stay with their current employers related to finances, safety and security, equipment and/or supplies, management, staff and patients.

Conclusions: In terms of Maslow's Hierarchy of Needs Theory, deficiency needs (physiological, safety and social needs) should be met by improved salaries revised on an annual basis, paying long-service and outstanding-service bonuses, and improving the safety and security, as well the available equipment and supplies, at institutions. Sufficient numbers of nurses should be employed and vacancies should be filled rapidly. However, not all changes required to enhance nurses' retention rates involve increased costs. Managers should lead by example and respect nurses, and encourage doctors as well as patients to do so, to meet nurses' self-esteem needs. Recognising and rewarding outstanding service would meet nurses' self-actualisation needs, as well as opportunities to further their education.

\section{Introduction and background information}

High turnover rates amongst nurses occur globally (Barney 2002:154). During 2008, 40.3\% of registered nurses' posts were reportedly vacant throughout South Africa (Health Systems Trust 2008). During the 1998 United Nations Conference for Trade (Hayes et al. 2006:244), it was estimated that South Africa lost US\$184 000 per annum for every South African, aged 25-35, who emigrated from this country. South African registered nurses are targeted by more affluent countries who offer better rewards, competitive incentives, registered growth, better resources and working conditions, safety, decreased workloads and a lower prevalence of HIV and AIDS (Oosthuizen \& Ehlers 2007:14). These aspects impact negatively on the remaining South African nurses, who have to bear the brunt of increased workloads under increasingly difficult circumstances.

Countries such as the United Kingdom (UK), Australia, New Zealand, Canada and the Middle East recruit registered nurses from South Africa. Registered nurses also discontinue practising (Ehlers 2003:81) when they reach retirement age, accept non-nursing jobs, or become fulltime housewives.

Statistics from the South African Nursing Council (SANC 2005b) show a decline of $42.0 \%$ in the number of nurses who completed their training in South Africa from 1996 to 2005. For the period 1996-2006, the population of South Africa grew by 14.36\% from 40583573 to 47390900 
(Statistics South Africa 2006). The ratio of registered nurses to population in South Africa is 1:471 on average, with marked differences between the nine provinces (SANC 2005c).

Globally, nursing shortages are complex and projected to intensify in future (Vance 2011:9) because of an ageing workforce, with the average age of practising nurses 44-46 years; declining numbers of enrolments at nursing schools; nurses pursuing other professions; and the perception that nursing offers fewer prospects than other careers. The demand for nursing care continues to increase, however, straining the remainder of practising registered nurses (Geyer 2001:4; Hospersa 2003:5; Nel 2001:5).

The current and projected future shortage of nurses in South Africa requires a focus on the retention of a stable nursing workforce. Ehlers (2003:65) indicates that the South African nurse shortage could be exacerbated by the retirement of the baby boomers, born between 1943 and 1964. The oldest baby boomers, aged 60 , would have reached retirement age by 2003 if they retired at age 60, or by 2008 if they retired at age 65 , with the youngest baby boomers retiring in 2029.

\section{Problem statement}

The high turnover rate of nurses in South African hospitals, combined with the low number of recruits entering the nursing profession, poses a threat to South Africa's healthcare delivery system. Unless health-care services prioritise to retain nurses within their organisations, South Africa's health-care system may become incapable of rendering health-care services. The research problem thus concerns the retention of registered nurses in the Gauteng Province, South Africa, and the steps that nurse managers and organisations could take to enhance the retention of registered nurses.

\section{Research questions}

The following research questions needed to be answered:

- What factors in the workplace could enhance the retention of nurses in the Gauteng Province?

- What actions can organisations and/or management take to create working conditions that would enhance the retention of registered nurses?

\section{Purpose and objectives of the study}

The purpose of the study was to reduce turnover rates amongst registered nurses by increasing the retention rates of nurses. The objectives of the study were to identify workplace-related factors, from the point of view of registered nurses, that could enhance the retention rates of nurses in the Gauteng Province, and to identify actions that organisations and/or management could implement to increase the retention rates of registered nurses. Based on these findings, recommendations will be made to enhance the retention of registered nurses in the Gauteng Province of South Africa.

\section{Definitions of key concepts}

Change: is the process of making something different from what it was (Sullivan \& Decker 2001:217). In this study it meant replacing established practices with new ones in order to enhance nurses' retention rates within a specific organisation.

Generations: is a term that applies to all the people born at a particular time and collectively grouped by those years when they were born. These people share birth years and significant life events at critical developmental stages (Duchscher \& Cowin 2004:494). Baby boomers were born between 1943 and 1964 (Zimmermann 2002:42) and will retire within the foreseeable future.

Health-care service: is a facility or institution that offers health-care services to patients at clinics or hospitals. In this report, the concept 'health-care service' will be used interchangeably with 'hospital' and 'organisation' and 'institution' where registered nurses are employed.

Job satisfaction: refers to attitudes and feelings that individuals have about their jobs. It includes the extent to which each individual's needs are fulfilled by the job that he or she performs (Ma, Samuels \& Alexander 2003:294).

Leadership: is the process of influencing and inspiring others so that they act willingly (Tappen 2001:5).

Nursing: according to Virginia Henderson, is a unique function which entails assisting the individual, whether ill or not, in performing activities that will contribute to health, recovery or peaceful death, that the individual would have performed unaided if he or she had the necessary strength, will or knowledge to do (Swansburg \& Swansburg 2002:82).

Nursing management: implies the process of preparing functions of planning, organising, staffing, leading or directing and controlling, or evaluating the activities of nursing in an organisation or its units, to deliver health care to patients (Swansburg \& Swansburg 2002:27).

Recruitment: is the process of adding new individuals to a population or group; or to attract someone to work for an organisation. It comprises activities that are interrelated to identify sources of talent to meet the organisation's needs by attracting sufficient numbers of the desired types of persons for specific jobs at specific times and places.

A registered nurse: is a person registered with the SANC as a nurse under Article 16 of the Nursing Act, No 33 of 2005, as amended. The terms 'registered nurse' and 'professional nurse' are used as synonyms.

Retention: refers to an organisation's ability to keep employees in their positions for as long as possible.

Turnover: implies the voluntary separation from an organisation by an individual who receives compensation from that particular organisation. If an employee leaves it is called 'turnover' (Shields \& Ward 2001:677). 


\section{Significance of the study}

Managers need to focus on workplace issues which, if addressed, would enable nurses to stay within their organisations. Nurses comprise the largest number of all health-care practitioners in South Africa, according to the African National Congress (ANC 1994:31). Improved retention rates of registered nurses, therefore, would enhance the quality of patient care, improve the morale of the remaining nurses, help to attract more recruits to nursing, and encourage non-practising nurses to re-enter the profession.

\section{Research method and design Design}

An exploratory and descriptive quantitative approach was used to identify factors influencing registered nurses' retention rates in the Gauteng Province.

\section{Population and sample}

The target population comprised nurses, registered with SANC, with addresses in the Gauteng Province. The SANC's statistician selected a $10.0 \%$ computerised representative sample from these records, which added up to 2676 names. The cost of sending out so many questionnaires would have been prohibitive, and thus a $20 \%(n=536)$ random sample, without replacement, was drawn from the names supplied by the SANC. Of the 536 posted questionnaires, only 116 were returned, despite sending out three sets of reminders. Of the 116 returned questionnaires, 8 could not be used, which added up to 108 usable questionnaires. This implies that only $20.1 \%(n=108)$ of the posted questionnaires comprised the sample for this study.

\section{Data collection instrument and data collection procedure}

Data were collected by means of self-administered questionnaires, constructed on the basis of similar studies' results. The questionnaire was pre-tested by 10 registered nurses working in the North West Province, who were excluded from the actual study. These 10 nurses considered the questions to be relevant and easily understandable. They required 30-40 minutes to complete the questionnaire. After the pre-test, the questionnaires were dispatched to respondents, together with covering letters, and stamped addressed envelopes for returning the completed questionnaires by post.

The questionnaire comprised closed-ended and open-ended items in three sections. Section A's 21 items (15 closed-ended and 6 open-ended items) of the questionnaire requested information about the registered nurses' personal data, employment sectors, career plans, as well as likes and dislikes in their current organisations.

Section B focussed on factors that might contribute to registered nurses' retention. This section comprised 68 closed-ended items graded on a 4-point Likert Scale ('strongly agree', 'agree', 'disagree', 'strongly disagree').
Section $C$ asked respondents to indicate the 10 most important factors, mentioned in section B of the questionnaire which, if changed for the better, would influence them to stay in their current organisations. This was an open-ended question.

Data collection was completed by 31 March 2007.

\section{Data analysis}

Quantitative descriptive procedures were used to analyse data, with the assistance of a statistician, using the Statistical Package for the Social Sciences (SPSS) version 14.

\section{Theoretical foundation of the study}

Maslow (ed. Booyens 1998:458) described a hierarchy of human needs, as the basis for individuals' motivation to behave in certain ways (Figure 1). Physiological, safety and social needs (the lowest three categories of needs) are regarded as deficiency needs which must be fulfilled before needs on the two higher levels (esteem needs and selfactualisation needs) can be met.

\section{Results}

The research results will be discussed according to the major categories of the questionnaires.

\section{Demographic and general information}

Of the 108 respondents, 7 (6.5\%) were male, and 101 (93.5\%) were female; 63 (58.3\%) were employed in the public sector and $43(39.8 \%)$ in the private sector, whilst $2(0.9 \%)$ failed to indicate their employment sectors. The respondents'

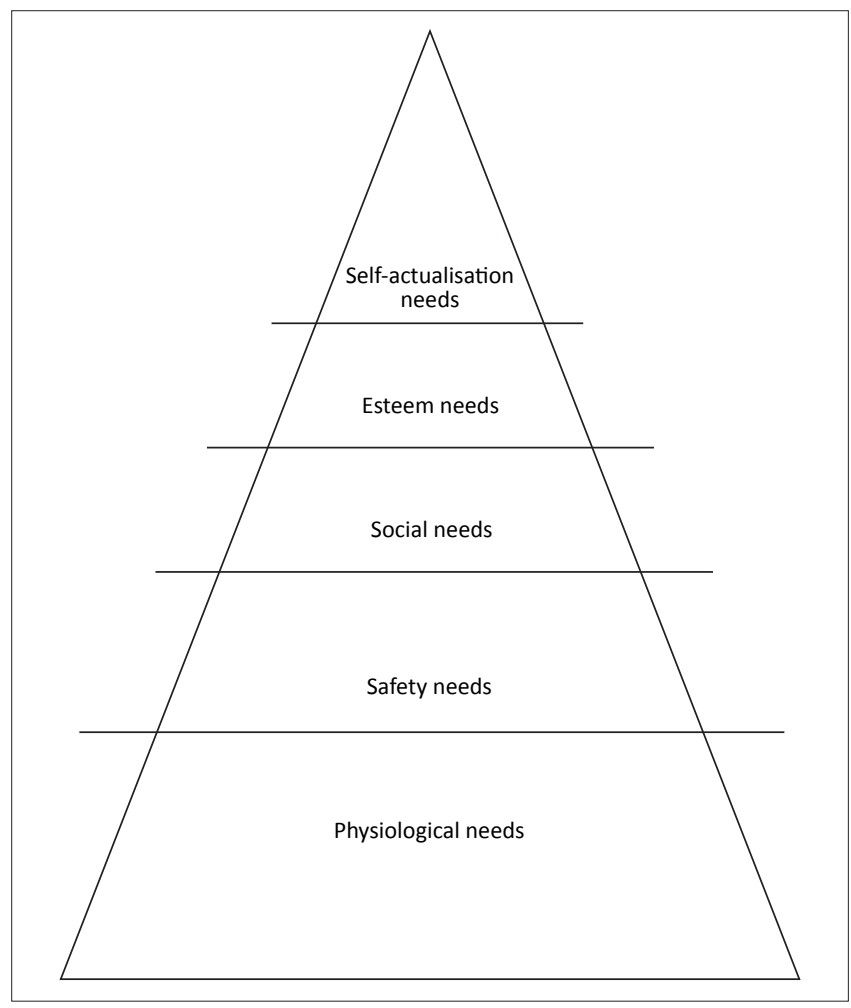

FIGURE 1: Maslow's Hierarchy of Needs 
employment categories were, professional nurse $(40.7 \%$; $n=44)$; senior professional nurse $(18.5 \% ; n=20)$; and chief professional nurse $(34.3 \% ; n=37)$. Seven respondents indicated 'other' categories without providing details.

Employment with their current organisations were grouped as $0-5$ years $(35.2 \% ; n=38$; of whom 23 had held their positions for 1 year or less); $6-10$ years $(27.8 \% ; n=30) ; 11-15$ years $(12.0 \% ; n=13)$; and 16 years or more $(25.0 \% ; n=27)$.

Of the 108 respondents, 50 (46.3\%) were baby boomers, comprising the largest group of respondents. This finding indicates the dire necessity of retaining nurses within their organisations as approximately half of the registered nurses in the Gauteng Province would reach retirement age within the foreseeable future.

\section{Respondents' intentions of leaving their employers}

Of the 108 respondents, 77 (73.1\%) had considered leaving their organisations, $24(22.2 \%)$ had not considered leaving, whilst $5(4.6 \%)$ did not respond to this question. The consideration of leaving could be regarded as the first sign that the individual might eventually leave, unless the factors that influence this intention could be addressed.

Of the 77 nurses who had considered leaving their employment organisations, $42(53.7 \%)$ intended to do so within the next year. These 77 respondents intended to stop working $(2.5 \% ; n=2)$; work overseas $(22.8 \% ; n=18)$, move from the public to the private sector $(20.3 \% ; n=16)$, move from rural to urban areas $(8.9 \% ; n=7)$, retire $(10.1 \% ; n=8)$, whilst $16(20.3 \%)$ wanted to raise families, go into business, change careers and engage in full-time studies. Only $3(3.8 \%)$ respondents were 'not sure'; 6 (7.6\%) merely stated that they were leaving, whilst 4 (5.1\%) did not specify their reasons for intending to leave their employers.

The registered nurses' reasons, in response to open-ended questions, for their intentions to leave their organisations were:

- financial $(39.2 \% ; n=31)$, including low salaries, no perks, poor overtime pay, inadequate benefits and lack of subsidies

- organisational $(30.4 \% ; n=4)$, increased workloads, poorly-resourced workplaces, lack of safety, dirty wards, violence in the workplaces and inflexible working hours

- management-related $(13.9 \% ; n=11)$, poor communication, poor management, lack of managerial support and leadership

- personal $(10.1 \% ; n=8)$, lack of job satisfaction, wanting to make career changes, lack of promotion opportunities, following family members abroad, venturing into new horizons, and furthering their studies

- other reasons $(6.3 \% ; n=5)$, for example, political instability, crime, nepotism, affirmative action and racism.

Research reports from other countries seem to support these findings. 'A consistently heavy workload increases job tension and decreases job satisfaction, which in turn, increase the likelihood of turnover' (Hayes et al. 2006:240). For every additional patient for whom a nurse must care, an estimated $23 \%$ increase in the odds of burnout and a $15 \%$ increase in the odds of job dissatisfaction have been determined empirically (Aiken et al. 2002:1988).

\section{Career plans for the following $\mathbf{2}$ years}

As many as $37(34.3 \%)$ registered nurses intended to emigrate, discontinue nursing practice, retire or make career changes within 2 years after the data collection phase. Of the $108(100 \%)$ respondents, $21(19.4 \%)$ had no plans, $6(5.6 \%)$ were undecided; 28 (25.9\%) would further their education; 12 $(11.1 \%)$ were planning to work abroad; $3(2.8 \%)$ intended to move into the nursing education field; $9(8.3 \%)$ contemplated retirement; $10(9.3 \%)$ wanted to complete their studies; 8 (7.4\%) wanted career changes; 2 (1.9\%) intended to start their own businesses, and 6 (5.6\%) offered no response.

\section{Suggested actions to amend registered nurses' dislikes}

Nurses were requested to indicate which changes in their workplaces would encourage them to remain with their current employers. Responses to this question, in descending order of importance, were grouped (Table 1).

The responses (Table 1) indicate that the three most important changes that would influence the retention of nurses were related to salaries, remuneration and other benefits (85.2\%; $n=92$ ), improving the working environment and working conditions $(77.8 \% ; n=84)$ and improved training of nurse managers $(72.2 \% ; n=78)$. Research findings about the impact of remuneration on nurses' turnover rates appear to be inconsistent, but seem to indicate that ' . . . improved pay would only have limited success unless accompanied by improved opportunities' (Hayes et al. 2006:243). These authors analysed 130 documents on global nurse turnover rates and concluded: 'Leadership that values staff contribution promotes retention, evidenced by consistent themes in the literature relating to autonomy, good working relationships and a management style that facilitates rather than directs' (Hayes et al. 2006:241).

TABLE 1: Changes that would enhance registered nurses' retention $(n=108)$.

\begin{tabular}{|c|c|c|}
\hline Change & $f$ & $\%$ \\
\hline Salary, remuneration and other benefits & 92 & 85.2 \\
\hline $\begin{array}{l}\text { Improving the workplace environment and } \\
\text { working conditions }\end{array}$ & 84 & 77.8 \\
\hline Training of nurse managers & 78 & 72.2 \\
\hline Training and education of registered nurses & 74 & 68.5 \\
\hline $\begin{array}{l}\text { Recognising and rewarding good } \\
\text { performance and loyalty }\end{array}$ & 70 & 64.8 \\
\hline $\begin{array}{l}\text { Nurse managers and doctors who show } \\
\text { respect for nurses as professionals and } \\
\text { people }\end{array}$ & 67 & 62.0 \\
\hline Enforcing safety in the workplace & 61 & 56.5 \\
\hline $\begin{array}{l}\text { Rewarding additional qualifications and } \\
\text { achievements }\end{array}$ & 56 & 51.9 \\
\hline More time for patient care & 53 & 49.1 \\
\hline $\begin{array}{l}\text { Improving communication between registered } \\
\text { nurses, management and authorities }\end{array}$ & 46 & 42.6 \\
\hline
\end{tabular}
source: Orenaldata and authorities

Source: Original data

$f$, frequency. 


\section{Factors influencing nurses' intentions to remain with their current employers}

In response to each of these 68 closed-ended items, identified from the literature review as influencing nurses' retention rates, the registered nurses had to indicate whether they 'agreed strongly', 'agreed', 'disagreed' or 'disagreed strongly'. The categories 'agreed strongly' and 'agreed' were combined as indicating positive responses; similarly 'disagreed' and 'disagreed strongly' were also combined to indicate negative responses. Only items that scored at least $90.0 \%$ positive responses are included (Table 2 ).

\section{Discussion of the most important factors that might enhance nurses' retention rates}

\section{Financial factors}

Of the 26 factors that were identified as influencing nurses' retention by at least $90.0 \%$ of the respondents, 8 were financial issues. A competitive salary $(94.4 \% ; n=102)$ was very important, but the annual revision of salaries $(95.4 \%$; $n=103$ ) was more important. Although South African nurses' salaries had increased, such increases were sometimes only implemented after country-wide strikes by nurses. The annual revision of nurses' salaries would re-assure nurses about the continued competitiveness of their salaries, without embarking on protracted strikes. Annual revisions of salaries, if comparable to the inflation rate, would enable nurses to maintain their living standards without seeking other employment with better remuneration. This would enable nurses to meet their physiological and safety and security needs (the two lowest categories of Maslow's hierarchy as seen in Figure 1). Research reports, however, seem to be inconsistent with regard to the influences of remuneration on nurses' turnover rates (Hayes et al. 2006:243). In the UK, Shields's and Ward's (2001:677) study indicated that dissatisfaction with promotion and training opportunities had a greater impact on nurses' turnover rates than nurses' workloads or salaries.

Most nurses $(93.5 \% ; n=101)$ considered incentives for working unsocial hours to be an important issue that affected nurses' decisions to remain with their current employers. Hung (2002:37) reported that long shifts and overtime, working during weekends or holidays and night shifts were associated with nurses' turnover rates. Unusual working hours make it difficult for nurses to meet their social needs, at level three of Maslow's Hierarchy of Needs (see Figure 1).

Rewards for outstanding performance $(92.6 \% ; n=100)$ and retirement benefits $(91.7 \% ; n=99)$ were also important considerations that influenced nurses' retention rates. Rewarding outstanding performance could be a challenging endeavour and should be carried out according to clear-cut guidelines. If managed effectively however, such rewards could motivate nurses to provide outstanding service, and at the same time enhance nurses' levels of job satisfaction and their retention rates.

TABLE 2: Aspects that would influence registered nurses' retention $(n=108)$.

\begin{tabular}{|c|c|c|c|c|c|c|}
\hline \multirow[t]{2}{*}{ Aspect } & \multicolumn{2}{|c|}{ Strongly agree } & \multicolumn{2}{|c|}{ Agree } & \multicolumn{2}{|c|}{ Total agree } \\
\hline & $n$ & $\%$ & $n$ & $\%$ & $N$ & $\%$ \\
\hline Annual revision of salary & 88 & 81.5 & 15 & 13.9 & 103 & 95.4 \\
\hline Zero tolerance policy on victimisation & 68 & 63.0 & 35 & 32.4 & 103 & 95.4 \\
\hline Safety rules and regulations & 61 & 56.5 & 42 & 38.9 & 103 & 95.4 \\
\hline Safe working place & 70 & 64.8 & 32 & 29.6 & 102 & 94.4 \\
\hline A competitive salary & 95 & 88.0 & 7 & 6.5 & 102 & 94.4 \\
\hline Adequate supplies and equipment & 78 & 72.2 & 24 & 22.2 & 102 & 94.4 \\
\hline Incentives for working unsocial hours & 81 & 75.0 & 20 & 18.5 & 101 & 93.5 \\
\hline Advancement opportunities in the organisation & 71 & 65.7 & 30 & 27.8 & 101 & 93.5 \\
\hline Making new employees feel at home & 59 & 54.6 & 42 & 38.9 & 101 & 93.5 \\
\hline Creating more nursing positions to ease workload & 71 & 65.7 & 30 & 27.8 & 101 & 93.5 \\
\hline Filling vacant positions more quickly & 79 & 73.1 & 22 & 20.4 & 101 & 93.5 \\
\hline Counselling after traumatic events & 57 & 52.8 & 43 & 39.8 & 100 & 92.6 \\
\hline Reward for outstanding performance & 74 & 68.5 & 26 & 24.1 & 100 & 92.6 \\
\hline Support from colleagues & 61 & 56.5 & 40 & 37.0 & 101 & 92.6 \\
\hline Retirement benefits & 70 & 64.8 & 29 & 26.9 & 99 & 91.7 \\
\hline Certificate or qualification bonus & 75 & 69.4 & 24 & 22.2 & 99 & 91.7 \\
\hline Health-care benefits (medical aid or insurance) & 67 & 62.0 & 32 & 29.6 & 99 & 91.7 \\
\hline Long-service bonus at 5 -year intervals & 71 & 65.7 & 27 & 25.0 & 98 & 90.7 \\
\hline Continuous feedback from management regarding performance & 61 & 56.5 & 38 & 35.2 & 99 & 91.7 \\
\hline In-service education at the workplace & 59 & 54.6 & 40 & 37.0 & 99 & 91.7 \\
\hline Respected by patients and family & 50 & 46.3 & 49 & 45.4 & 99 & 91.7 \\
\hline Recognition of outstanding performance & 76 & 70.4 & 22 & 20.4 & 98 & 90.7 \\
\hline Respect from managers and doctors & 78 & 72.2 & 20 & 18.5 & 98 & 90.7 \\
\hline Fair and consistent application of disciplinary procedures and policies & 62 & 57.4 & 36 & 33.3 & 98 & 90.7 \\
\hline Respect for diversity & 41 & 38.0 & 57 & 52.8 & 98 & 90.8 \\
\hline
\end{tabular}

Source: Original data

$n$, Given as a means of number; $N$, total number. 
It could be expected that retirement benefits would be of particular importance to the $50.9 \%(n=55)$ nurses who would retire in the near future. Retirement benefits were important, however, to $91.7 \%(n=99)$ of the respondents, which indicates that attractive retirement benefits could influence nurses of all ages to remain with their current employers.

Other financial issues that would influence more than $90.0 \%$ of the respondents to remain with their current employers were, bonuses for additional qualifications $(91.7 \% ; n=99)$, healthcare benefits and/or medical aid insurance $(91.7 \% ; n=99)$, and long-service bonuses at 5-year intervals $(90.7 \%$; $n=98)$. Medical aid insurance is expensive in South Africa, and it is understandable that any assistance in this regard would exert a powerful influence on nurses' decisions to seek other employment opportunities. Long-service bonuses at 5-yearly intervals could be powerful motivators to many nurses to remain with one employer for at least 5 years. Although these long-service bonuses would cost money, retaining nurses' services for at least 5 years would save money that would otherwise be spent on advertisements, interviews, and the orientation programmes of newly appointed nurses. All these financial issues could be categorised as falling within the lower three categories of Maslow's Hierarchy of Needs (see Figure 1), implying that these needs should be met before the nurses could aspire to meet some needs at the esteem and self-actualisation levels.

Obtaining additional qualifications demand financial and personal investments. Nurses' additional qualifications could enable them to render improved services to their patients and to their employers. Consequently bonuses for additional qualifications could benefit the successful nurses, and motivate others to pursue further qualifications to the ultimate benefit of themselves, their patients and their employers. By supporting nurses to improve their qualifications, and by recognising such accomplishments formally, nurses will be enabled to meet some of their needs at the highest levels of Maslow's Hierarchy of Needs, at the esteem and self-actualisation levels.

Cyr (2005:563) explored factors that influence early retirement of 4000 nurses from eight hospitals. These nurses wanted to work past their retirement ages if their work environments could be modified by optimising hourly rates and receiving financial incentives, developing 'back-to-work' programmes, reducing patient assignments, and increasing flexible work schedules. Flexibility was explained as accommodating nurses who had mobility problems, as well as 'less-work-forless-pay' programmes.

\section{Safety factors}

Safety rules and regulations were regarded as important factors in influencing their retention decisions $(95.4 \% ; n=103)$ and being employed in a safe working place was equally important $(95.4 \% ; n=103)$. Safety and security needs are high amongst South Africans because they live in a country with a high crime rate. Ito et al. (2001:232) found that nurses' perceived risks of assaults in their workplaces predicted their turnover rates. Any health-care institution needs to implement safety and security measures. Viewed, however, against the importance attached to this issue by $95.4 \%$ of the respondents, continued efforts to enhance the safety and security of all staff members could enhance the retention rates of nurses. Nurses' safety and security needs must be met (the second lowest category in Maslow's Hierarchy of Needs) for their retention rates with their current employers to improve.

\section{Equipment and resources}

Most nurses (94.4\%; $n=102$ ) would consider remaining with their current employers if their institutions would ensure that they had adequate supplies and equipment. Ongoing audits of problems concerning hospital supplies and equipment could address this issue. Unless nurses have adequate supplies and equipment, they cannot practise safely, which implies that their safety and security needs (level 2 in Maslow's Hierarchy of Needs) remains unfulfilled, making it impossible to actualise higher order needs.

\section{Staff-related factors}

Numerous staff-related factors could influence nurses' decisions to remain with their current employers. Rafferty, Ball and Aiken found that:

... autonomy, control over resources, relationships with doctors,
emotional exhaustion, and decision-making to be correlated
with one another as well as having a relationship with nurse-
assessed quality of care and nurse satisfaction.

(Rafferty, Ball and Aiken 2001:ii32)

Almost all (95.4\%; $n=103)$ nurses indicated that zero tolerance of victimisation would influence their decisions to remain with their current employers. Investigating and remedying victimisation incidences would be expected from effective management and should not incur additional expenses. This task would be facilitated if nurses could submit anonymous reports of perceived incidences of victimisation in 'general comments boxes' placed at strategic places throughout the institution, provided that action is taken on all such reports. Social aspects comprise part of the third level of Maslow's Hierarchy of Needs and constitute a deficiency need, and that should be met to enable nurses to meet higher order needs. Addressing social aspects need not incur huge financial costs to meet nurses' social needs.

Other staff-related factors that would contribute to the retention of registered nurses include, adequate advancement opportunities in the organisation $(93.5 \% ; n=101)$; making new employees feel at home $(93.5 \% ; n=101)$; creating more nursing posts to ease the workload $(93.5 \% ; n=101)$; filling vacant posts more quickly (93.5\%; $n=101)$; providing counselling services after traumatic events $(92.6 \% ; n=100)$; receiving support from colleagues (92.6\%); and respecting diversity $(90.7 \% ; n=98)$. These aspects would help nurses to actualise their needs at the higher levels of esteem and self-actualisation, and would contribute to the retention of 
nurses. Adequate advancement opportunities' costs could be offset against repeated advertisements, appointments and orientations of new nurses. This would also decrease the need for filling vacant nursing positions, reduce the effort and costs incurred by orientating new staff members, and possibly reduce the need for increasing the number of nursing positions, because more experienced nurses (promoted to higher ranks) could manage nursing activities more effectively than newly appointed junior nurses.

By providing counselling services to nurses after traumatic experiences, the individual nurses concerned, as well as their colleagues, their patients and ultimately the entire institution, could benefit. Nurses who suffer from posttraumatic stress cannot render effective services as their own well-being are adversely affected, and they are also unable to provide support to their colleagues. Effective counselling services would assist nurses to meet their needs at Maslow's lowest two levels, and enable them to meet their needs at higher levels.

\section{Management-related factors}

More than $90.0 \%$ of the nurses indicated that six managementrelated issues would affect their decisions to remain with their current employers. These included that management should lead by example $(92.6 \% ; n=100)$; ensure continuous feedback about performance $(91.7 \% ; n=99)$; provide inservice education at the workplace $(91.7 \% ; n=99)$; recognise outstanding performance $(90.7 \% ; n=98)$; respect nurses management, and doctors should do likewise $(90.7 \% ; n=98)$; and apply disciplinary procedures and policies fairly and consistently $(90.7 \% ; n=98)$. Bratt et al. (2000:307) reported that a management style, which 'facilitates rather than directs' and which recognises staff contributions, promoted the retention of nurses.

Implementation of all these aspects would seem to be reasonable expectations from effective management. These aspects would enable registered nurses to meet their needs at the two highest levels of Maslow's Hierarchy of Needs, esteem and self-actualisation. Implementing, monitoring and enhancing these aspects would not necessarily imply additional expenses for employers.

\section{Patient-related factors}

Only one aspect in this category was identified by $90.7 \%$ $(n=98)$ respondents who indicated that if patients and their families showed respect to nurses, it would influence their decisions to remain with their current employers. Nurses interact with patients and lack of respect could complicate such interactions by impacting negatively on nurses' levels of job satisfaction. In a milieu where managers and doctors and nurses show respect to each other, patients would be more likely to show respect to all health-care workers, enabling nurses to meet their social (third lowest category) and esteem (second highest category) of needs, in terms of Maslow's Hierarchy of Needs.

\section{Limitations of the study}

Only 108 registered nurses returned their completed postal questionnaires, which did not allow for the generalisation of the research results to the entire Gauteng Province. It cannot be assumed that those nurses who returned their completed questionnaires had the same ideas about factors influencing the retention of registered nurses, as those who failed to do so. More than one-third of the questionnaires were completed by chief professional nurses, whose retention might be influenced by factors different from those that influence the retention of registered nurses who occupy more junior professional positions. The breaking down of the influences on the answers about the respondents' employment levels might have added richer data about factors that influence the retention of nurses at different employment levels.

All the respondents did not complete all items on the questionnaires and their reasons for not responding could not be ascertained. This might have been possible during interviews. Individual in-depth interviews might produce better insight into the phenomenon of the retention of nurses.

Cross tabulations of results indicated no marked differences between nurses from different generations or between nurses working in the public versus private sectors.

These differences between publicly employed versus privately employed nurses, as well as the differences amongst nurses belonging to different generations, might have become apparent during interviews.

\section{Recommendations}

Nurses' retention rates could be enhanced if employers were to implement the following recommendations.

Nurses' salaries need to be competitive and revised on an annual basis. Rewards for outstanding services and retirement benefits should be revised and should remain competitive. Medical aid insurance should be subsidised and long-service bonuses paid after 5 years of service.

Ongoing improvements of safety and security measures, and of equipment and supplies, should be maintained. Anonymous recommendations, placed in suggestion boxes, could help to identify weaknesses from the nurses' perspectives.

Anonymous reports of perceived victimisation incidents would help to identify and address these issues, and would help to retain nurses in an organisation. Other staff-related issues that need to be addressed include the provision of adequate promotion opportunities, an increase in the number of nursing posts, more rapid filling of vacant nursing posts, orientation of new employees, and the provision of counselling services.

Management could influence nurses' retention rates in leading by example, and by providing continuous feedback 
about performance standards, by respecting nurses and encouraging both doctors and patients to do likewise, as well as by rewarding outstanding performance. Consistent and fair application of disciplinary policies must be maintained.

In conclusion, the importance of the retention of nurses in South Africa's health-care services cannot be overemphasised:

In a time of global shortages, retention of nurses has become the key to the survival and growth of health care agencies. Generally, job satisfaction of nurses directly impacts their intent to stay or leave ... and therefore their retention.

(Kwak et al. 2010:1296)

Although increasing recruitment of nurses and improved compensation may help offset nurses' shortages in the short term, researchers suggest that administrative interventions to improve quality of work life are more effective long-term interventions in reducing turnover...

(Hayes et al. 2006:240)

Reducing turnover rates of registered nurses requires more than merely sporadically improved salaries.

\section{Reliability and validity}

Pre-testing the instruments and encouraging the respondents to give critical comments, enhanced the content validity. Face validity was determined through consultations with a statistician and two nurse researchers.

Three methods of reliability testing are stability, equivalence and internal consistency. Research and nursing management experts assessed the instrument's items for internal consistency, implying that the instrument's items addressed factors that might influence nurses' retention rates. Data from respondents' replies to different items of the questionnaire were compared and no major discrepancies were noted, indicating equivalence and stability. No specific tests were conducted to measure equivalence and stability.

Of the 68 items listed on the questionnaire, 26 scored at least $90.0 \%$ positive responses as factors that would influence registered nurses' decisions to remain with their current employers. These 26 factors were grouped according to influences pertaining to finances, safety, equipment, staff, management and patients. The factors related to finances, safety and equipment could be categorised as falling into Maslow's category of deficiency needs, at the lowest two hierarchical levels (Figure 1).

\section{Ethical considerations}

Approval was obtained from the Research and Ethics Committee of the Department of Health Studies, University of South Africa. No signed consent to guarantee anonymity, was required. Willingness to complete and return the questionnaire was accepted as the individual respondent's consent to participate in the study.
Relevant information, as well as the first author's contact details, was supplied to each respondent. Respondents remained anonymous to ensure that responses could not be linked to any particular individual. Anonymity was maintained by requiring no names on the questionnaires, and confidentiality by keeping the completed questionnaires locked up.

\section{Conclusions}

Competitive salaries revised on an annual basis, incentives for working unsocial hours, bonuses for additional qualifications, rewards for outstanding services, retirement benefits, medical aid insurance and long-service bonuses at 5 -year intervals would influence nurses to remain with their current employers. Adequate safety and security at their workplaces, as well as adequate supplies and equipment, would enhance nurses' retention rates by meeting their deficiency needs in terms of Maslow's Hierarchy of Needs Theory.

Staff-related factors that would influence nurses' decisions to remain in their current institutions included zero tolerance of victimisation, promotion opportunities within the institutions, making new employees feel at home, quickly filling vacant posts, increasing the number of nursing posts, receiving counselling after traumatic encounters, support from colleagues, and respecting diversity. These aspects would help nurses to meet their needs at the physiological, safety and security, social, as well as esteem levels.

Management could influence nurses' retention rates in leading by example, and by providing continuous feedback about performance standards, by respecting nurses, by rewarding outstanding performance, and by applying disciplinary procedures consistently and fairly. Respect from patients would also influence nurses' decisions to remain with their current employers. Addressing these issues would enable nurses to meet their needs at the esteem and selfactualisation levels.

Cross tabulations of results indicated no marked differences between nurses from different generations or between nurses working in the public versus private sectors.

\section{Acknowledgements}

The authors wish to thank all the nurses who completed and returned questionnaires. Without their input this research would have been impossible. We also wish to thank the South African Nursing Council for supplying the requested name and address labels.

\section{Competing interest}

The authors declare that they have no financial or personal relationship(s) which may have influenced them inappropriately in writing this paper. 


\section{Authors' contributions}

K.E.M. conducted the study for her doctoral thesis, V.J.E. was the supervisor and M.J.O. was the joint supervisor. The first author obtained permission for the study and collected the data. The second and third authors guided the research process from its conception until its conclusion. The second and corresponding author assumed the major responsibility for the writing of the article, based on the doctoral thesis, and for continuing with the process until publication, with input from the other authors.

\section{References}

African National Congress., 1994, A national health plan for South Africa, Bahr Maseru.

Aiken, L.H., Clarke, S.P., Sloane, D.M., Sochalski, J. \& Silber, J.H., 2002, 'Hospital Nurse Staffing and Patient Mortality, Nurse Burnout, and Job Dissatisfaction' Journal of the American Medical Association 228(16), 1987-1993. http://dx.doi. Journal of the American Medical
org/10.1001/jama.288.16.1987

Barney, S.M., 2002, 'The Nursing Shortage: Why is it happening?' Journal of Health Management 47(3), 153-155.

Booyens, S.W., (ed.), 1998, Dimensions of nursing management, 2nd edn., Juta, Kenwyn.

Bratt, M.M., Broome, M., Kelber, S. \& Lostcoco, L., 2000, 'Influence of Stress and Nursing Leadership on Job Satisfaction of Pediatric Intensive Care Unit Nurses', American Journal of Critical Care 9(2), 307-317. PMid:10976354

Cyr, J.P., 2005, 'Retaining Older Hospital Nurses and Delaying their Retirement', Journal of Nursing Administration 35(12), 563-567.

Duchscher, J.E. \& Cowin, L., 2004, 'Multigenerational Nurses in the Workplace', Journal of Nursing Administration 34(11), 493-501. PMid:15586070

Ehlers, V.J., 2003, 'Registered Nurses' Requests to Remove their Names from the South African Nursing Council's Register. Part 1: Introduction and Literature review', Health SA Gesondheid 8(2), 63-69.

Fletcher, C.E., 2001, 'Hospital RN's Job Satisfaction and Dissatisfactions', Journal of Nursing Administration 31(6), 324-331. http://dx.doi.org/10.1097/00005110200106000-00011

Geyer, N., 2001, 'Where are the nurses?' HASA Newsletter, October, 4-6.

Hayes, L.J., O'Brine-Pallas, L., Duffield, C., Shamian, J., Buchan, J., Hughes, F., 2006, 'Nurse Turnover: a literature review', International Journal of Nursing Studies 43(10), 237-263. http://dx.doi.org/10.1016/j.ijnurstu.2005.02.007, PMid:15878771
Health Systems Trust (HST), 2008, 'Percentage of professional nurse posts vacant', viewed 14 April 2008, from http:// indicators.hst.org.za/healthstats/256/data

HOSPERSA, 2003, 'Shortage of Nurses in Public Service', Nursing Today 9(2), 5

Hung, R., 2002, 'A note on Nurse Self-scheduling', Nursing Economics 20(1), 37-39. PMid:11892546

Ito, H., Eisen, S.V., Sederer, L.I., Yamada, O. \& Tachimori, H., 2001, 'Factors affecting Psychiatric Nurses' Intention to Leave their Current Job', Psychiatric Services 52(2), 232-234. http://dx.doi.org/10.1176/appi.ps.52.2.232, PMid:11157125

Kwak, C., Chung, B.Y., Xu, Y. \& Eun-Jung, C., 2010, 'Relationship of Job Satisfaction with Perceived Organizational Support and Quality of Care among South Korean Nurses: a questionnaire Survey', International Journal of Nursing Studies 47(10), 1292-1298.

Ma, C., Samuels, M.E. \& Alexander, J.W., 2003, 'Factors that influence Nurses' Job satisfaction', Journal of Nursing Administration 33(5), 293-299.

Nel, I., 2001, 'What's happening to nursing?', Nursing Update 25(5), 18.

Oosthuizen, M.J. \& Ehlers, V.J., 2007, 'Factors that may Influence South African Nurses' decisions to Emigrate', Health SA Gesondheid 12(2), 14-26.

Rafferty, A.M., Ball, J. \& Aiken, L.H., 2001, 'Are Teamwork and Registered Autonomy Compatible, and do they result in Improved Hospital Care?', Quality in Health Care 10(suppl ii), ii32-ii37. http://dx.doi.org/10.1136/qhc.0100032, PMCid:1765758

Shields, M.A. \& Ward, M., 2001, 'Improving Nurse Retention in the National Health Service in England: the Impact of Job Satisfaction on Intentions to Quit' Journal of Health Economics 20(5), 677-701. http://dx.doi.org/10.1016/S0167 6296(01)00092-3

South Africa, 2005, Nursing Act (Act no 33 of 2005), Government Printer, Pretoria. PMCid:1720242

South African Nursing Council, 2005a, 'Ratio of registered nurses to population', viewed 20 October 2005, from http://www.sanc.co.za

South African Nursing Council, 2005b, 'Output of 4yr program from South African nurse training institutions', viewed 12 April 2006, from http:www.sanc.co.za

South African Nursing Council, 2005c, 'Age distribution: registered nurses and midwives', viewed 12 October 2005, from http:www.sanc.co.za

Statistics South Africa, 2006, 'Population of South Africa: 1996-2006', viewed 02 November 2006, from http:www.sanc.co.za

Strachota, E., Normandin, P., O'Brien, N., Clary, M. \& Krukow, B., 2003, 'Reasons Registered Nurses Leave or Change Employment Status', Journal of Nursing Administration 33(2), 111-117. http://dx.doi.org/10.1097/00005110-20030200000008

Sullivan, E.J. \& Decker, P.J.C., 2001, Effective leadership and management in nursing, 6 th edn., Jones \& Bartlett, Upper Saddle River.

Swansburg, R.C. \& Swansburg, R.J., 2002, Introduction to management and leadership for nurse managers, Jones \& Bartlett, Sudbury (Massuchusetts).

Tappen, R.M., 2001, Nursing leadership and management: concepts and practice, 4th edn. F.A. Davis (eds.), Philidelphia.

Vance, D.E., 2011, 'Nursing around the World: a Perspective on Growing Concerns and the Shortage of Care', Nursing Research and Reviews 1(9), 9-13.

Zimmermann, P.G., 2002, Nursing management secrets, Hanley \& Belfus, Philadelphia. 